\title{
Melatonin Deficiency Confers Tolerance to Multiple Abiotic Stresses in Rice via Decreased Brassinosteroid Levels
}

\author{
Ok Jin Hwang and Kyoungwhan Back *(B) \\ Department of Biotechnology, College of Agricultural and Life Sciences, Chonnam National University, \\ Gwangju 61186, Korea; smilax@jnu.ac.kr \\ * Correspondence: kback@chonnam.ac.kr; Tel.: +82-62-530-2165
}

Received: 17 August 2019; Accepted: 16 October 2019; Published: 18 October 2019

\begin{abstract}
Melatonin has long been recognized as a positive signaling molecule and potent antioxidant in plants, which alleviates damage caused by adverse conditions such as salt, cold, and heat stress. In this study, we found a paradoxical role for melatonin in abiotic stress responses. Suppression of the serotonin $\mathrm{N}$-acetyltransferase 2 (snat2) gene encoding the penultimate enzyme in melatonin biosynthesis led to simultaneous decreases in both melatonin and brassinosteroid (BR) levels, causing a semi-dwarf with erect leaf phenotype, typical of BR deficiency. Here, we further characterized snat2 rice in terms of grain morphology and abiotic stress tolerance, to determine whether snat2 rice exhibited characteristics similar to those of BR-deficient rice. As expected, the snat2 rice exhibited tolerance to multiple stress conditions including cadmium, salt, cold, and heat, as evidenced by decreased malondialdehyde (MDA) levels and increased chlorophyll levels, in contrast with SNAT2 overexpression lines, which were less tolerant to stress than wild type plants. In addition, the length and width of grain from snat2 plants were reduced relative to the wild type, which is reminiscent of BR deficiency in rice. Other melatonin-deficient mutant rice lines with suppressed BR synthesis (i.e., comt and $t 5 h$ ) also showed tolerance to salt and heat stress, whereas melatonin-deficient rice seedlings without decreased BR levels (i.e., $t d c$ ) failed to exhibit increased stress tolerance, suggesting that stress tolerance was increased not by melatonin deficiency alone, but by a melatonin deficiency-mediated decrease in BR.
\end{abstract}

Keywords: abiotic stress; brassinosteroid; cadmium; cold; gibberellin; heat; melatonin; salt

\section{Introduction}

Since melatonin was first identified in plants in 1995 [1,2], a growing body of research suggests that it plays roles as both a pleiotropic signal molecule and a potent antioxidant molecule in plants [3,4], similar to its reported roles in animals $[5,6]$. Early studies showed that treatment of plants with exogenous melatonin produced diverse physiological effects including high temperature tolerance [7], early flowering [8], cold tolerance [9,10], coleoptile and root growth [11,12], and salt tolerance [13]. Increased levels of endogenous melatonin were first produced in plants through ectopic overexpression (OE) of the serotonin N-acetyltransferase (SNAT) gene from Chlamydomonas reinhardtii in transgenic tomato [14], and subsequently by $\mathrm{OE}$ of the human SNAT and $N$-acetylserotonin $O$-methyltransferase (ASMT) genes in transgenic tobacco [15]. Of note, the transgenic tobacco plants exhibited enhanced antioxidant capacity in concert with simultaneous increases in the levels of antioxidant enzymes and the antioxidant glutathione, consistent with the effects of exogenous melatonin treatment described above.

SNAT and ASMT are the final two enzymes in the melatonin biosynthetic pathway in plants (Figure 1a), and are responsible for the synthesis of $N$-acetylserotonin and melatonin, respectively [16]. 
Plant ASMT genes were first cloned from rice in 2013 [17], followed by the cloning of the SNAT1 gene in 2013 [18] and the SNAT2 gene in 2016 [19]. Serotonin is the only precursor used in the synthesis of melatonin. It is derived from tryptophan by two successive enzymatic reactions carried out by tryptophan decarboxylase (TDC) and tryptamine 5-hydroxylase (T5H). Although the above four enzymes are crucial for melatonin biosynthesis in plants, SNAT appears to be the pivotal enzyme because it is highly conserved from cyanobacteria to land plants [20] and is present as at least two distinct isogenes that share very low amino acid homology [19]. The most prominent phenotype caused by melatonin depletion resulting from the disruption of melatonin biosynthetic pathway genes is a semi-dwarf with erect leaf phenotype, which was recently observed in SNAT2 suppression (snat2) rice lines [21]. By contrast, no such phenotype was observed in SNAT1 suppression rice lines [22]. A $T 5 H$ knockout mutant $(t 5 h)$ rice line and a caffeic acid $O$-methyltransferase (COMT) suppression (comt) rice line also exhibited semi-dwarf with erect leaf, brassinosteroid (BR)-deficient phenotypes comparable to that of snat2 rice through the suppression of melatonin synthesis due to the high ASMT activity of COMT [23]. Alternatively, serotonin can be converted into 5-methoxytryptamine (5MT) by ASMT or COMT, followed by melatonin synthesis by SNAT (Figure 1a) [24]. Due to its high $K_{\mathrm{m}}$ toward serotonin by ASMT, serotonin-5MT-melatonin pathway may occur under stress conditions whereas serotonin-NAS-melatonin pathway works under normal growth conditions [16].

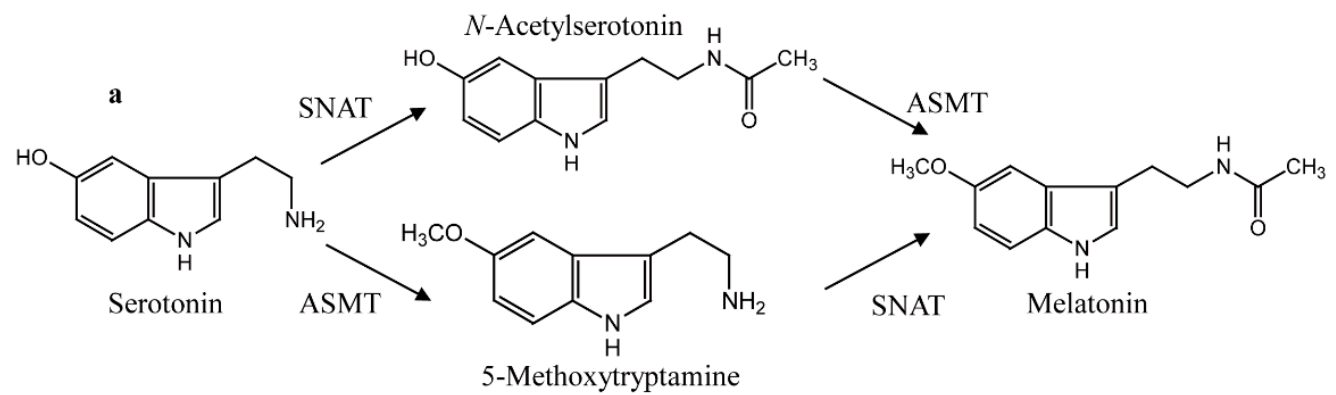

b

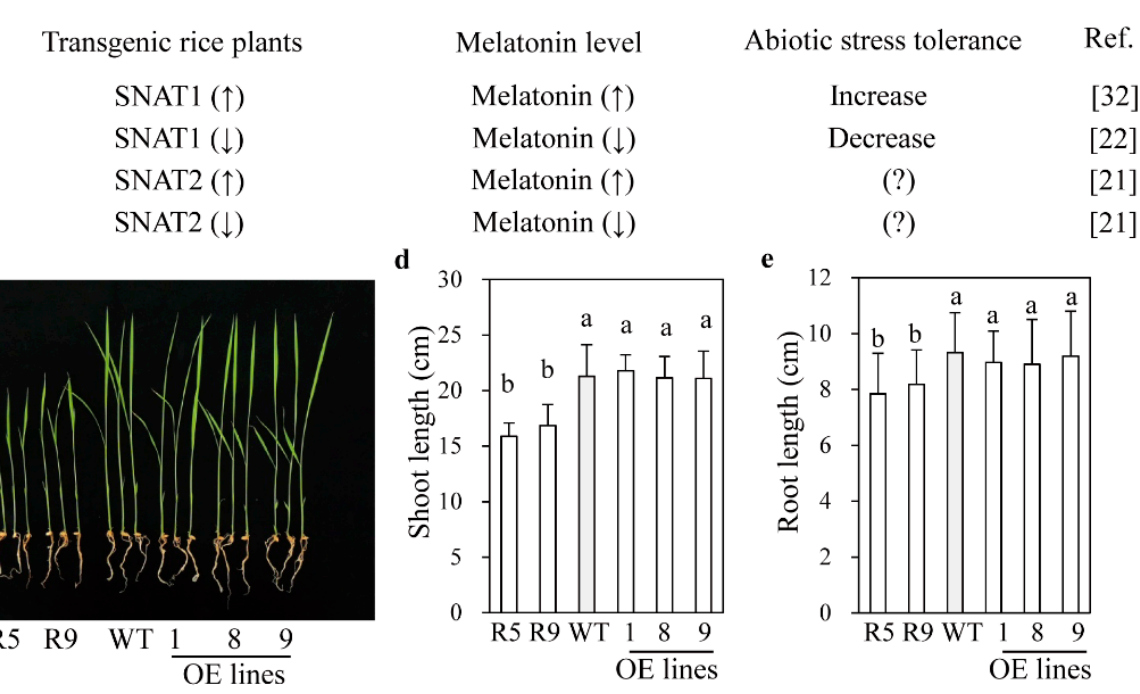

Figure 1. Phenotypes of snat2 and SNAT2 OE rice seedlings. (a) Melatonin biosynthetic pathway in plants. (b) Relationship between SNAT gene expression and stress tolerance. (c) Seedling phenotypes. (d) Shoot length. (e) Root length. Germinated seeds were grown under a 14-h light/10-h dark cycle for 12 days. Values are means \pm standard deviation from three independent experiments. Different letters indicate significant differences, as determined by a post-hoc Tukey's honestly significant difference (HSD) test at $p<0.05$. R5 and R9: SNAT2 RNAi lines; OE, SNAT2 overexpression lines; WT, wild type. $\uparrow$ denotes increase and $\downarrow$ means decrease on melatonin level. ? denotes no data available.

In addition to the above effects of exogenous melatonin application or endogenous increase by ectopic $\mathrm{OE}$, melatonin has also been implicated in germination, growth, and defense against abiotic 
and biotic stresses. An increase in melatonin is associated with enhanced resistance to stress, possibly due to direct and indirect effects of the potent antioxidant activity of melatonin [3,25]. Importantly, a recent report shed new light on the possible role of melatonin as a signaling molecule that regulates skotomorphogenesis, which is characterized by rapid hypocotyl growth in darkness [26]. A decrease in the endogenous melatonin level caused a decrease in BR levels, leading to a semi-dwarf with erect leaf phenotype typical of BR-deficient and BR-signaling mutants [21]. However, a melatonin decrease is not necessarily coupled with a BR decrease; BR decrease occurs in a melatonin biosynthetic gene-specific manner. The suppression of T5H (t5h), SNAT2 (snat2), and COMT (comt) resulted in decreased BR levels, whereas suppression of TDC $(t d c)$ and SNAT1 (snat1) expression did not [23].

BR is a well-known plant hormone involved in skotomorphogenesis and abiotic stress tolerance in plants [27]. Exogenous application of BR confers protection against cold, salt, heat, and heavy metal stresses [28], as has also been shown for melatonin [25]. Paradoxically, some BR-deficient and BR-signaling mutants displayed tolerance to cold [29], salt [30], and drought [31], whereas BR OE mutants were more sensitive to the same stresses [29]. Therefore, we examined whether melatonin-deficient mutants exhibiting decreased BR levels are also tolerant to abiotic stress in a manner similar to BR mutants. In this study, we found that snat 2 rice plants producing decreased levels of melatonin and BR exhibited increased tolerance to a number of abiotic stresses, whereas SNAT2 OE plants exhibited stress tolerance comparable to or less than that of the wild type. Moreover, melatonin-deficient $t 5 h$ mutant and comt rice plants with decreased BR levels also exhibited stress tolerance similar to that of snat 2 rice.

\section{Results}

\subsection{Phenotypes of snat2 and SNAT2 OE Rice Seedlings}

The previously generated snat2 rice line, in which SNAT2 expression is suppressed by RNAi, produces low melatonin levels and exhibits a semi-dwarf with erect leaf phenotype in conjunction with decreased BR levels [21]. The SNAT2 mRNA was reduced two-fold in the snat 2 whereas increased more than five-fold in SNAT2 OE rice based on qPCR analyses. By contrast, the erect leaf phenotype was not observed in snat1 rice line [22], which exhibits decreased melatonin levels and a lower level of tolerance to salt and cold than the wild type, while SNAT1 OE rice plants produced higher melatonin levels, and exhibited significant tolerance to cadmium and delayed senescence (Figure 1b) [32]. Therefore, we examined whether snat2 and SNAT2 OE rice exhibited similar abiotic stress responses to snat1 and SNAT1 OE rice. When snat2 and SNAT2 OE rice seeds were germinated and grown in soil in pots for 12 days under a 14-h light/10-h dark cycle, the snat2 seedlings exhibited shorter shoot and root lengths than wild-type seedlings, but no difference was observed between the SNAT2 OE lines and the wild type (Figure 1c-e). The second leaf angles were significantly smaller in the snat 2 rice than in the wild type, while the SNAT2 OE lines showed leaf angles comparable to those of the wild type [21]. Some SNAT2 OE plants exhibited increased leaf angles relative to the wild type, but the differences were not statistically significant. These data indicated that snat 2 rice resembled BR-deficient rice, which is characterized by a dwarf and erect leaf phenotype, while SNAT2 OE rice was dissimilar to BR-proficient rice with the increased leaf angle [33].

\subsection{Grain Phenotypes and Yield Performance}

Rice grain size is affected by BR levels, with BR-deficient rice plants producing small grains [34,35]. To verify whether grain size was affected in snat 2 rice, we investigated yield components of snat 2 rice grown in a paddy field. As shown in Figure 2, the grain length was longer in SNAT2 OE plants than in the wild type, but was shorter in snat2 plants than in the wild type (Figure 2a,b). Grain width was reduced in snat2 plants, but no difference was observed between SNAT2 OE and wild-type grains (Figure 2c,d). Due to the smaller grain size, the 1000-grain weight was less for snat2 than for the wild type (Figure 2e). The rice inflorescence morphology differed significantly between the wild-type 
and snat 2 plants, with the snat 2 inflorescences possessing more primary branches resulting in higher spikelet numbers per plant (Figure 2f,g); meanwhile, the inflorescence morphology of SNAT2 OE plants was similar to that of the wild type. The higher numbers of spikelets per plant in snat 2 successfully compensated for the reduced grain size, leading to no yield penalty relative to the wild type (Figure $2 \mathrm{~h}$ ). The adult snat 2 rice showed a semi-dwarf phenotype (Figure 2i). Increased spikelet number per panicle had also been observed in the $d 61$ rice BR receptor mutant [36], but not in the BR biosynthetic mutant, dwarf4-1 [37]. The same 1000-grain weight in SNAT2 OE with long grain length relative over wild type was attributed to the reduced thickness of SNAT2 OE seed relative over wild type. These data suggest that, with respect to panicle number, the effects of snat2-mediated melatonin reduction are more closely associated with BR signaling than with BR deficiency.
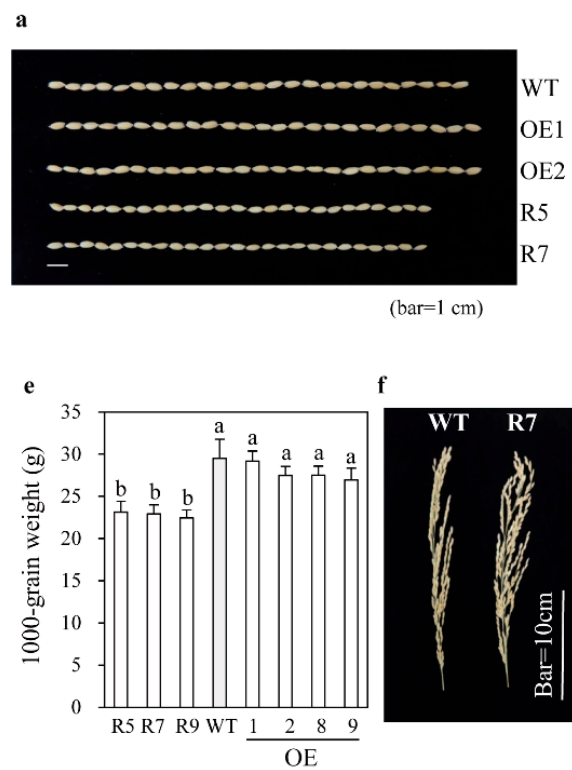

(bar=1 cm)
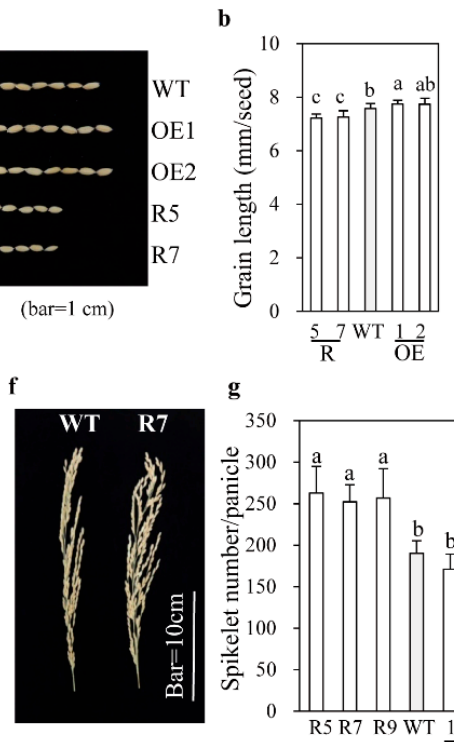

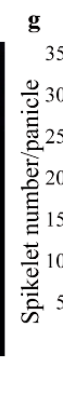

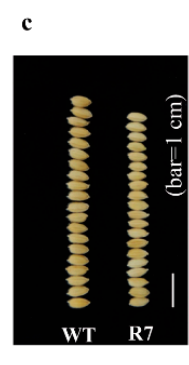

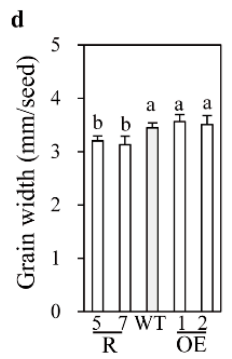

h

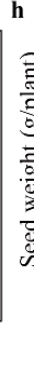

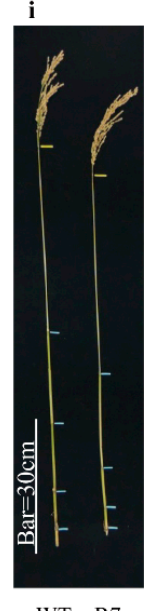

WT $\quad$ R7

Figure 2. Rice grain and panicle morphology. (a) Photograph showing lengths of grains from WT, OE, and snat2 lines. (b) Grain lengths $(n=200)$. (c) Photograph showing widths of grains from snat2 line and WT. (d) Grain widths $(n=200)$. (e) 1000-grain weights $(n=4)$. (f) Representative panicle morphologies. (g) Spikelet numbers $(n=20)$. (h) Seed weights $(n=10)$. (i) Culm length of adult rice. $\mathrm{T}_{2}$ homozygous rice seeds were germinated and grown in a paddy field. Different letters indicate significant differences as determined by a post-hoc Tukey's HSD test at $p<0.05$.

\subsection{Altered GA Sensitivity in snat2 Rice}

In plants, the dwarf phenotype results from a defect in either BR or GA signaling and biosynthesis, indicative of a close relationship between BR and GA [38]. In this context, the BR biosynthesis mutant, d11, produced lower GA levels than the wild type. To study the relationship between BR reduction and GA levels in snat2 rice, we performed a GA-sensitivity assay. Seven-day-old snat2 seedlings were shorter than wild-type and SNAT2 OE seedlings (Figure 3a,b). Expression levels of the active GA biosynthetic gene, GA3ox2, were enhanced in snat2, whereas expression of the inactive GA biosynthetic gene, GA20x3, was downregulated relative to that in wild-type and SNAT2 OE plants (Figure 3c). As reported previously [21], the major BR biosynthetic gene, DWARF4, was expressed at lower levels in snat2 plants, but in this study we observed no difference in its expression in SNAT2 OE relative over wild-type (Figure 3c). Because grain phenotype and dwarfism can be easily connected to the relationship between $B R$ and auxin [39], we also measured the expression levels of a representative auxin responsive gene IAA6 [40]. The IAA6 was downregulated in the snat 2 rice and SNAT2 OE rice lines except OE9, suggestive of a possible involvement of auxin as well. The increase in GA3ox2 expression may suggest an increase in GA levels or possible feedback regulation compensating for a decrease in GA in the snat2 rice. In the presence of the GA inhibitor PAC, all rice seedlings showed similar shoot 
lengths of approximately $10 \mathrm{~mm}$ (Figure 3d). By contrast, addition of $\mathrm{GA}_{3}$ resulted in increased shoot length in a $\mathrm{GA}_{3}$ dose-dependent manner in all rice seedlings; however, the lengths of snat 2 seedlings were shorter than those of wild-type seedlings at all concentrations of $\mathrm{GA}_{3}$. Of note, the shoot lengths of the SNAT2 OE seedlings appeared to increase under high concentrations of $\mathrm{GA}_{3}$, such as 10 and $100 \mu \mathrm{M}$, but the increase in shoot length varied depending on the lines (Figure 3d). These data indicate that snat2-mediated melatonin deficiency is closely linked to reduced BR levels when analyzed by ELISA method, as well as increased GA insensitivity. To further assess GA involvement, we performed a germination test under light/dark conditions. As shown in Figure 4, the germination rate of snat 2 rice was severely reduced at $48 \mathrm{~h}$, suggesting increased GA insensitivity, whereas the germination rate of SNAT2 OE rice was increased at $24 \mathrm{~h}$, suggesting enhanced GA sensitivity. Overall germination rates after $72 \mathrm{~h}$ did not differ between the wild type and SNAT2 OE (Figure 4a,b). The bioactive BR content was lower in snat2 than in the wild type, while no significant difference in BR content was observed between SNAT2 OE and the wild type (Figure 4c). GA content was unaltered in both SNAT2 OE and snat2 (Figure 4d). Thus, it can be concluded that the increase in GA biosynthetic gene expression was caused by feedback regulation, owing to decreased GA sensitivity. In summary, we suggest that the decreased melatonin levels in the snat2 plants led to reduced BR levels, which increased GA insensitivity, while GA sensitivity appeared to increase slightly in the SNAT2 OE rice lines.

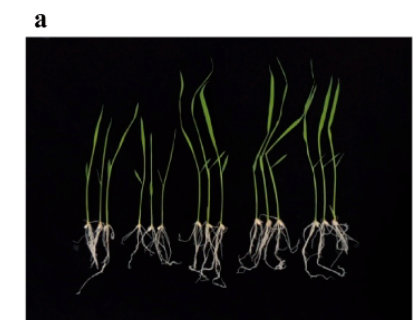

R7 R9 WT OE1 OE9

c

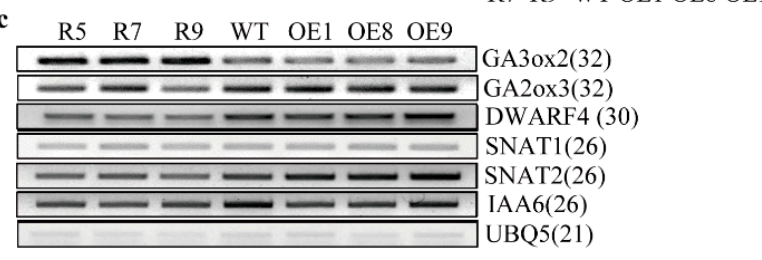

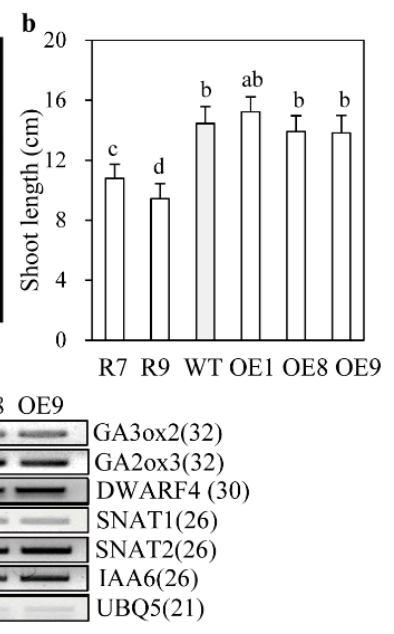

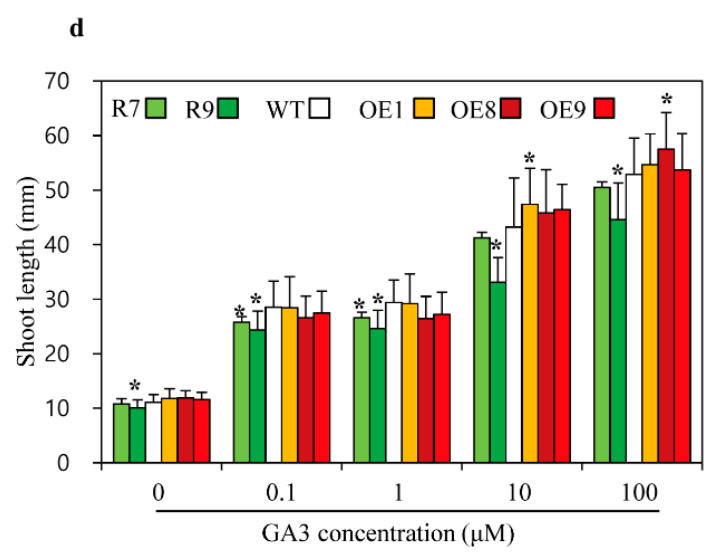

Figure 3. Gibberellic acid (GA) and brassinosteroid (BR) biosynthetic gene expression levels and GA sensitivity assay. (a) Phenotypes of various rice seedlings grown for 7 days. (b) Shoot lengths. (c) Expression levels of GA and BR biosynthetic genes determined by reverse transcription-polymerase chain reaction (RT-PCR). (d) Shoot lengths of GA-treated seedlings. Rice seedlings were grown for 7 days in half-strength MS medium (a-c). Rice seeds were grown at various concentrations of $\mathrm{GA}_{3}$ after pretreatment with the GA biosynthesis inhibitor paclobutrazol (PAC) (d). Different letters and asterisks indicate significant differences as determined by a post-hoc Tukey's HSD test at $p<0.05$. GenBank accession numbers are AB056519 (GA3ox2), AK101713 (GA2ox3), Os03g12660 (DWARF4), and Os03g13170 (UBQ5). Numbers in parentheses indicate the number of PCR cycles. 

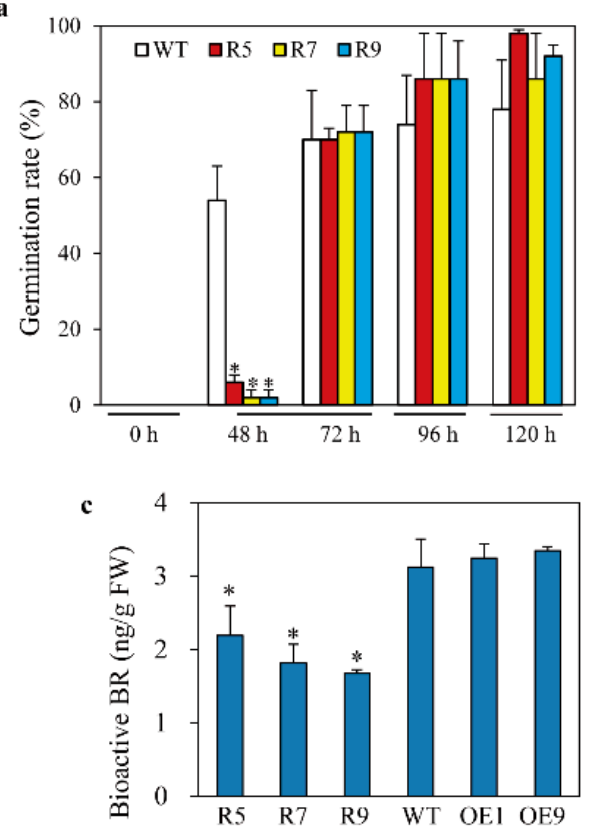
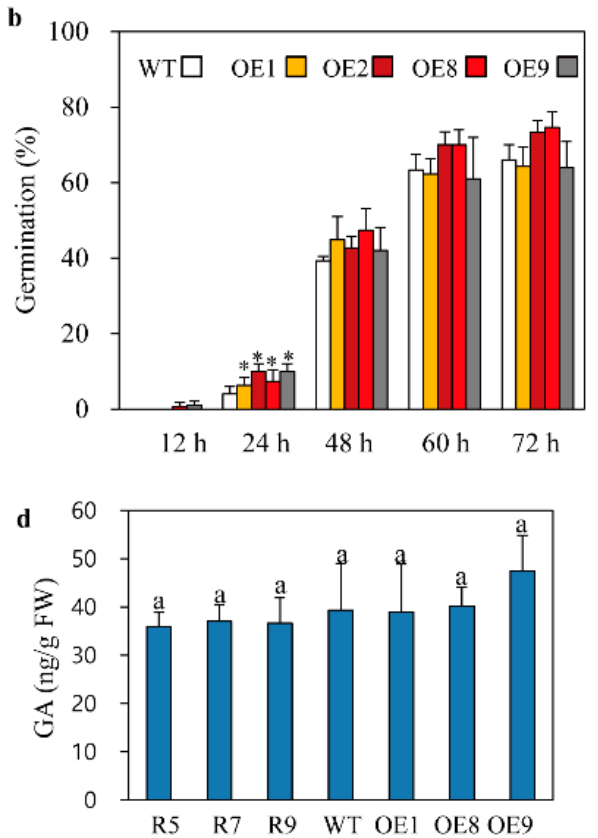

Figure 4. Germination rates and bioactive BR and GA levels. (a) Time course of snat2 rice germination. (b) Time course of SNAT2 OE rice germination. (c) Bioactive BR levels. (d) Bioactive GA levels. Rice seeds were germinated under 14-h light/10-h dark long day conditions for the germination test. BR and GA levels were quantified by ELISA using 7-day-old rice seedlings grown in half-strength MS medium. Different letters and asterisks indicate significant differences as determined by a post-hoc Tukey's HSD test at $p<0.05$. Data represent the mean \pm standard deviation of triplicate experiments.

\subsection{Enhanced Tolerance to Cadmium Stress in Melatonin-Deficient snat2 Rice}

Both reduced BR levels and increased GA insensitivity in snat2 rice may result in the retarded seedling growth. These two factors have been known to enhance abiotic stress tolerance in plants [41,42]. Thus, we examined whether snat 2 rice plants exhibit tolerance to abiotic stress. We challenged rice seedlings with cadmium stress, which induces melatonin synthesis in rice [23]. As shown in Figure 5, melatonin levels were dramatically reduced in the snat2 rice, whereas a slight increase was observed in the SNAT2 OE lines relative to the wild type (Figure 5a,b). In contrast to many previous results in which melatonin was positively associated with enhanced abiotic stress tolerance [3,4,32], the melatonin-deficient snat2 plants paradoxically showed higher tolerance to cadmium stress than the wild type, as evidenced by higher chlorophyll contents and lower MDA levels than in the wild type (Figure $5 c, d$ ). These results are attributed to the BR deficiency and increased GA insensitivity of snat 2 rice, and not to the removal of potential direct harmful effects of melatonin accumulation (since melatonin has no toxic effect in most plant species) [43]. As opposed to the snat2, the SNAT2 OE exhibited less cadmium tolerance than wild type (Figure $5 \mathrm{c}, \mathrm{d}$ ). 

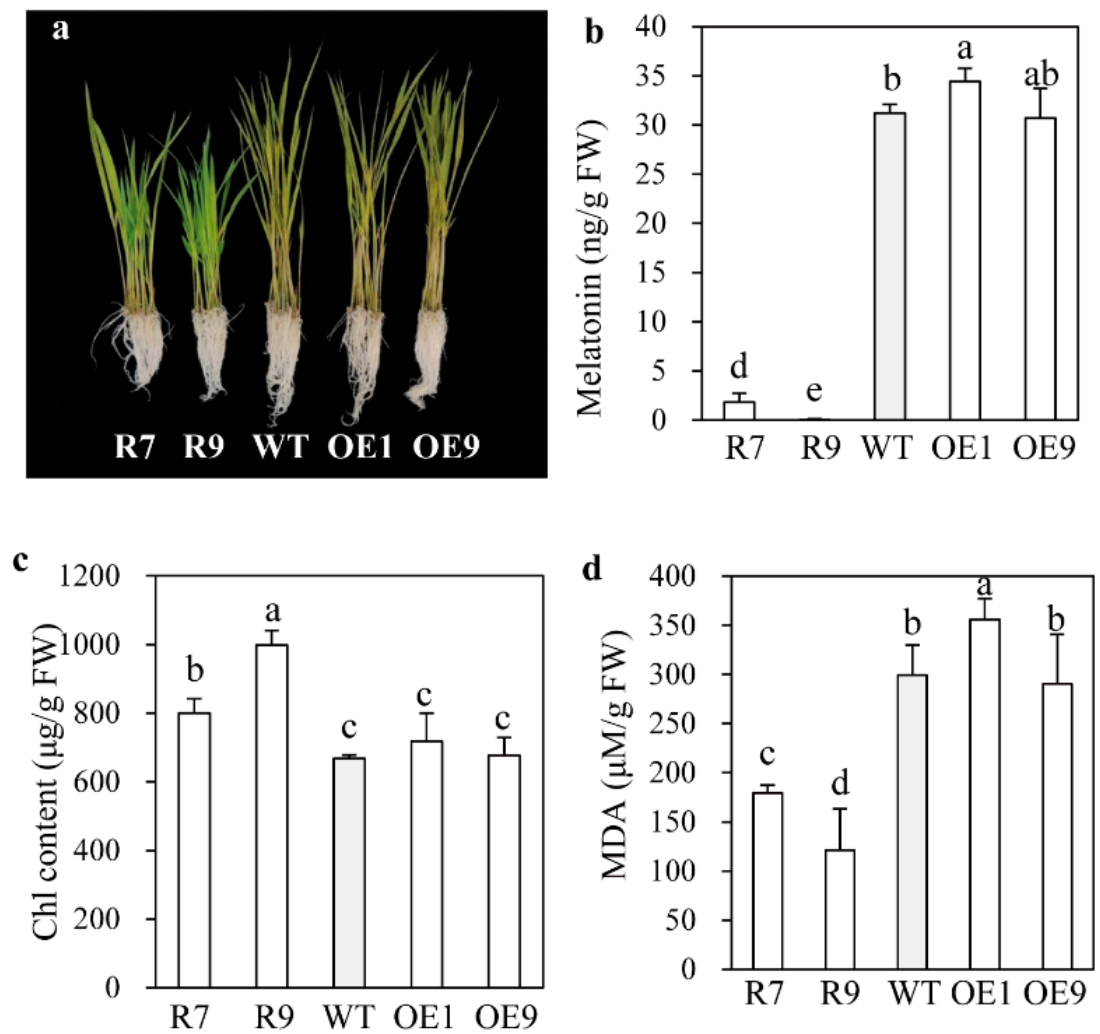

Figure 5. Effects of cadmium treatment on melatonin, chlorophyll, and malondialdehyde (MDA) levels in rice. (a) Rice seedlings after cadmium treatment. (b) Melatonin levels. (c) Chlorophyll content. (d) MDA content. Seven-day-old seedlings were challenged with cadmium $(500 \mu \mathrm{M})$ for 3 days under a 14-h light/10-dark photoperiod. Shoot tissue was employed for analyses. Different letters indicate significant differences as determined by a post-hoc Tukey's HSD test at $p<0.05$.

\subsection{Melatonin-Deficient snat2 Rice Plants Exhibit Resistance to Salt, Cold, and Heat Stress}

In addition to cadmium tolerance, the snat 2 plants also exhibited increased salt stress tolerance, whereas the SNAT2 OE lines were more susceptible to salt stress, as indicated by their MDA levels (Figure $6 \mathrm{a}, \mathrm{b}$ ). Accordingly, the average survival rate of snat 2 plants under salt stress was $55 \%$, while those of the wild type plants and the SNAT2 OE lines were only $30 \%$ and less than $20 \%$, respectively (Figure 6c). In response to cold stress, the survival rate of snat2 rice was higher than that of the wild type based on MDA and chlorophyll contents (Figure 7), whereas the SNAT2 OE lines exhibited lower survival rates than the wild type. Heat stress produced high MDA levels in the wild type, whereas the MDA levels in snat2 rice were three times lower on average than in the wild type (Figure 8). In contrast to salt and cold stress, the SNAT2 OE lines showed similar heat stress response relative to the wild type. Collectively, these results showed that melatonin-deficient snat 2 rice exhibited enhanced tolerance to multiple abiotic stress conditions, consistent with the results of previous studies of plants with reduced BR and GA levels [41,42]. 

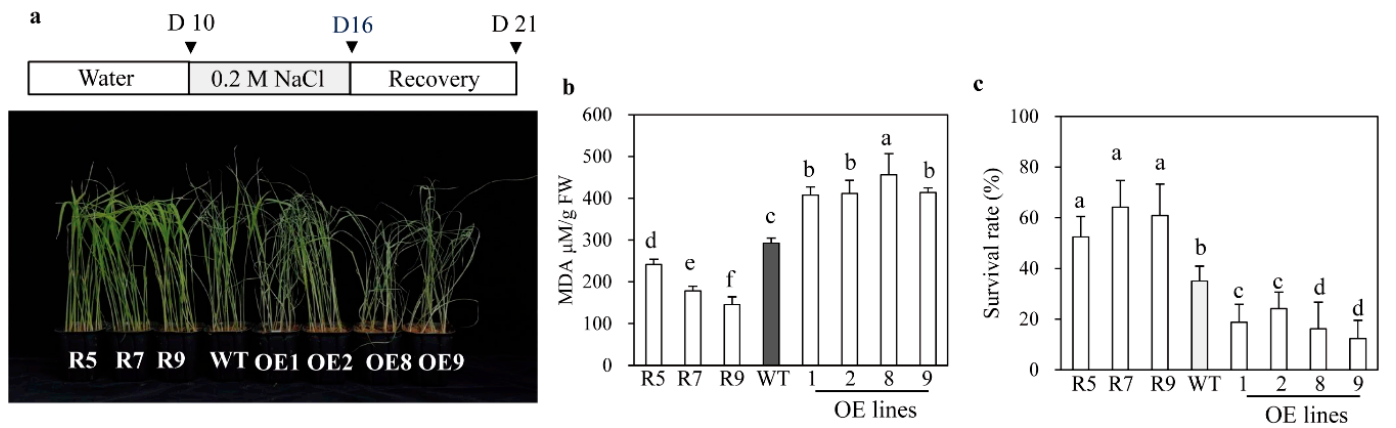

Figure 6. Response to salt treatment. (a) Rice seedlings after recovery from salt stress treatment. (b) MDA content. (c) Survival rates. Ten-day-old rice seedlings were immersed in $0.2 \mathrm{M} \mathrm{NaCl}$ solution for 6 days and then allowed to recover for 5 days. D denotes the time course day. Different letters indicate significant differences as determined by a post-hoc Tukey's HSD test at $p<0.05$.
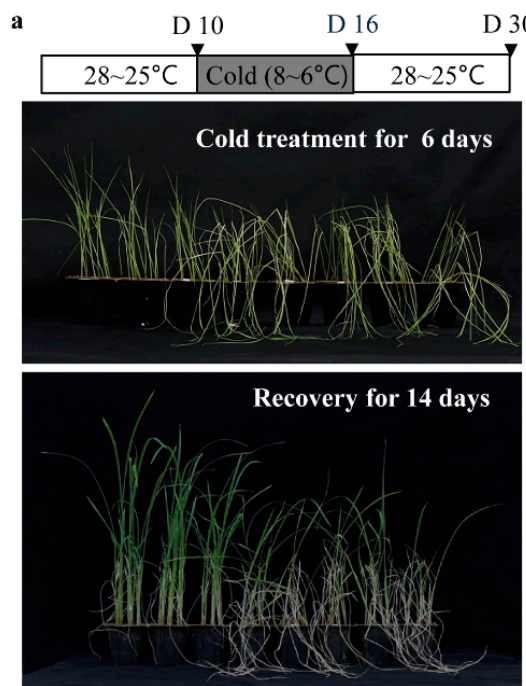

R5 R7 R9 WT OE1 OE2 OE8 OE9
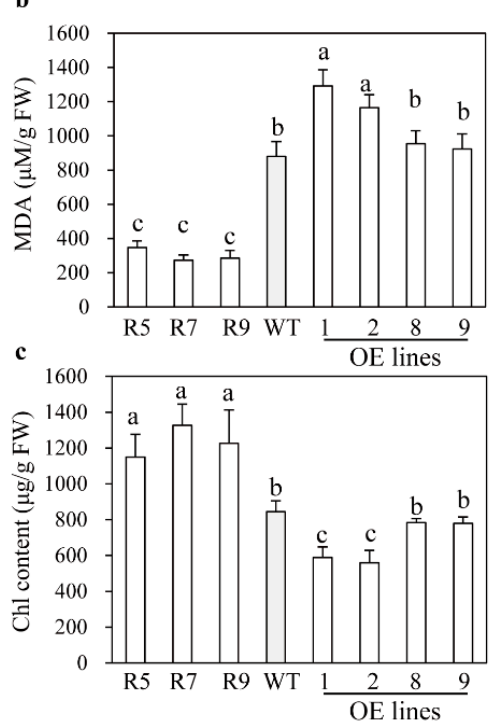

Figure 7. Response to cold treatment. (a) Rice seedlings after cold treatment and recovery from cold stress. (b) MDA content. (c) Chlorophyll content. Ten-day-old rice seedlings were exposed to cold stress at $6-8{ }^{\circ} \mathrm{C}$ for 6 days and then allowed to recover for 14 days at $25-28{ }^{\circ} \mathrm{C}$. D denotes the time course day. Different letters indicate significant differences as determined by a post-hoc Tukey's HSD test at $p<0.05$.

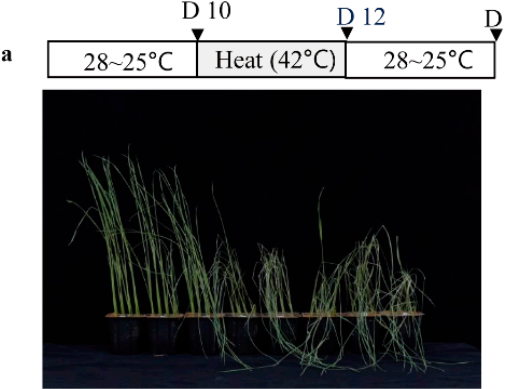

R5 R7 R9 WT $\frac{128 \quad 9}{\text { OE lines }}$

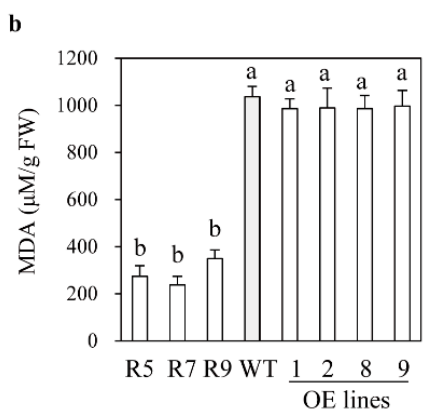

Figure 8. Response to heat treatment. (a) Seedlings after recovery from heat stress. (b) MDA content. Ten-day-old rice seedlings were challenged with heat stress at $42^{\circ} \mathrm{C}$ for 2 days and then allowed to recover for 1 day. Different letters indicate significant differences as determined by a post-hoc Tukey's HSD test at $p<0.05$. 


\subsection{Enhanced Tolerance to Salt and Heat Stress in Other Types of Melatonin-Deficient Rice}

To determine whether other genetic cultivars with melatonin deficiency also confer tolerance to abiotic stress in rice seedlings, we employed two RNAi rice lines and one mutant rice line known to produce lower levels of melatonin than the wild type. The $t d c$ RNAi rice lines did not exhibit altered BR levels, whereas comt RNAi rice exhibited reduced BR levels [23]. Lower levels of melatonin and BR are produced in $t 5 h$ rice than in the wild type [23]. Seedlings of the snat2, comt, and $t 5 h$ melatonin-deficient lines exhibited significant tolerance to both salt and heat stress, but no tolerance was observed in the $t d c$ rice, as indicated by their MDA levels (Figure 9). This difference on abiotic stress responses was due to the lack of reduced BR levels in $t d c$ rice, in contrast with the reduced BR levels in the other types of melatonin-deficient rice relative to the wild type [23]. Based on the above observations, we conclude that endogenous melatonin deficiency is closely associated with enhanced abiotic stress tolerance only when melatonin deficiency is coupled with reduced BR levels.
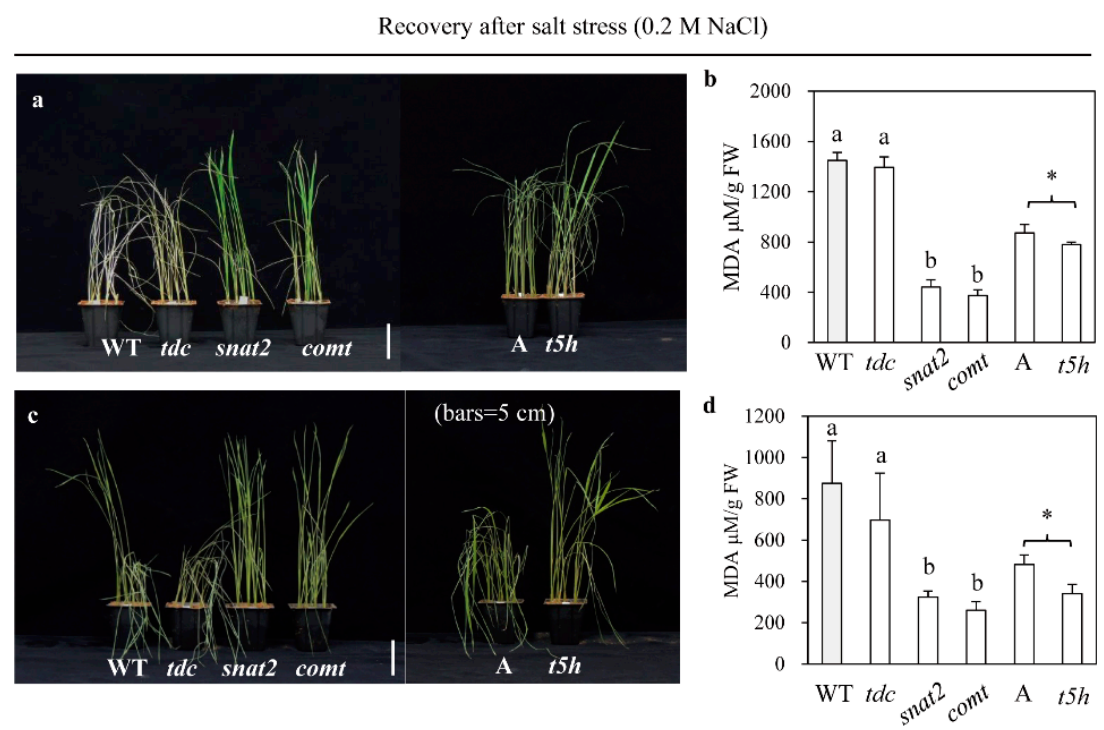

Recovery after heat stress $\left(42^{\circ} \mathrm{C}\right)$

Figure 9. Stress tolerance of melatonin-deficient rice mutant lines. (a) Salt-treated rice seedlings. (b) MDA levels after salt treatment. (c) Heat-treated rice seedlings. (d) MDA levels after heat treatment. Methods for salt and heat treatment are described in Figures 6 and 8, respectively. $t d c, T D C$ suppression rice; snat2, SNAT2 suppression R7 rice; comt, COMT suppression rice; A, Ashahi rice (wild type of $t 5 h$ mutant rice); $t 5 \mathrm{~h}, \mathrm{~T} 5 \mathrm{H}$ mutant rice. Different letters and asterisks indicate significant differences as determined by a post-hoc Tukey's HSD test at $p<0.05$.

\section{Discussion}

Melatonin has long been considered to be a positive regulator in plants, enhancing tolerance to various abiotic and biotic stresses including cold, heat, salt, and drought [4]. Various pharmacological studies have shown that exogenous melatonin treatments with concentrations ranging from $0.1 \mu \mathrm{M}$ to $1 \mathrm{mM}$ reduced damage caused by a number of abiotic stresses, as evidenced by decreased levels of reactive oxygen species (ROS), MDA, and electrolyte leakage, as well as increases in antioxidants and antioxidative enzymes [44-46]. The induction of tolerance to adverse environments by exogenous melatonin application appears to be due to the combined effects of the potent antioxidative activity of melatonin itself [6] and its role as a pivotal signaling molecule [47-49]. In addition, many molecular and genetic experiments have confirmed the results of the pharmacological studies mentioned above. For instance, gain of function analyses showed that plants overexpressing melatonin biosynthetic genes exhibited increased tolerance to cold [50], UV-B light [51], herbicide [52], drought [53-55], heat [56], salt [57], cadmium [32,58-60], and continuous light [61]. Complementary to the gain of function 
analyses, loss of function analyses via either suppression or knockout of melatonin biosynthesis demonstrated increased sensitivity to tunicamycin [49], high light [62], salt [63], senescence [22], and pathogens [64]. All of these data strongly suggest that melatonin plays a positive role in stress tolerance in plants.

In marked contrast to previous results, we found a paradoxical effect of melatonin. Even though the snat 2 rice plants produced low melatonin levels compared to the wild type, they proved to be tolerant to various abiotic stresses including cadmium, cold, salt, and heat, possibly because the snat 2 rice produced lower levels of BR than the wild type [21].

BR is a well-known plant hormone that controls multiple physiological processes throughout the entire life cycle of the plant, including seed germination, cell elongation, and skotomorphogenesis, as well as defense responses against various abiotic and biotic stresses [27]. Like melatonin, BR is synthesized in all plant cells without transport over long distances. Thus, its de novo synthesis and turnover are key factors that regulate BR levels. It is known that exogenous application of BR to plants improves protection against many adverse conditions such as cold, salt, drought, heat, and heavy metal stresses, by increasing the activities of antioxidant enzymes such as catalase, and the levels of glutathione and proline $[28,65]$. Interestingly, BR treatment also confers resistance to a broad range of diseases in tobacco and rice, in conjunction with increased yield, via its growth-promoting activity $[28,66]$. In contrast to exogenous BR treatment, increasing the level of endogenous BR through the ectopic OE of BR biosynthetic genes results in decreased tolerance to stress, while BR-deficient mutants exhibit increased drought tolerance via increased sensitivity to abscisic acid (ABA) [31]. A BR receptor mutant (bri1) exhibited cold tolerance, while BRI1-overexpressing Arabidopsis plants were more sensitive to cold stress, indicative of an inverse relationship between BR and stress tolerance [29,30].

Recently, a more detailed analysis of BR function showed that BR regulates cell elongation by modulating GA metabolism in rice [42]. Under physiological conditions, BR promotes GA production, while GA levels are reduced in BR-deficient mutants. However, treatment with excessive BR reduces GA levels through upregulation of GA inactivation genes, resulting in growth inhibition. By contrast, application of GA-inhibitors retards plant growth and increases tolerance to many abiotic stresses, including drought. Accordingly, GA application reverses enhanced stress tolerance in GA-inhibitor treated plants and GA-deficient mutants [4], suggesting that GA application will cause the plants to be less tolerant to various abiotic stresses. In addition, the suppression of IAA6 in the snat 2 was ascribed to BR decrease because IAA6 expression was dependent on BR [67]. In contrast, the similar suppression patterns of IAA6 in the OE lines without BR decrease remained unclear.

Based on the above observations, it is clear that melatonin deficiency leads to decreased BR levels, which in turn reduce GA sensitivity resulting in increased tolerance to multiple abiotic stresses such as cadmium, cold, heat, and salt (Figures 5-8). In this study, our examination on the effects of decreased BR levels were not limited to the melatonin-deficient snat 2 rice; we also examined the melatonin-deficient $t 5 h$ and comt rice lines, which also produced lower BR levels than the wild type [23]. All three of these rice lines were BR-deficient due to decreased melatonin levels, and exhibited enhanced tolerance to multiple abiotic stresses. However, the snat 1 and $t d c$ mutants did not exhibit suppressed BR levels even though both produced less melatonin than the wild type. Thus, it is tempting to speculate that melatonin exerts physiological functions in a BR-dependent or -independent manner in plants, although the detailed mechanism remains to be determined (Figure 10). For example, SNAT1 is involved in melatonin synthesis independent of BR synthesis, and its suppression leads to decreased melatonin levels resulting in decreased tolerance to abiotic stress and reduced yield, possibly due to increased ROS levels (Figure 10a). TDC functions in a similar manner to SNAT1 in terms of melatonin synthesis and abiotic stress responses. Conversely, snat2 resulted in decreased melatonin in conjunction with decreased BR, which conferred tolerance to cadmium, cold, salt, and heat stress (Figure 10b). Like SNAT2, the suppression of other melatonin biosynthetic genes, including T5H and COMT, also conferred tolerance to cold and heat stress in a similar way to BR decrease [23]. This suppression of BR levels in response to decreased melatonin appears to be mediated by a melatonin 
receptor [68], but its direct role remains elusive. In particular, the grain phenotypes of snat2 rice were identical to those of the BR-deficient and BR-signaling mutants reported thus far, confirming that decreased melatonin is coupled to decreased BR even at the reproductive stage $[34,36]$.
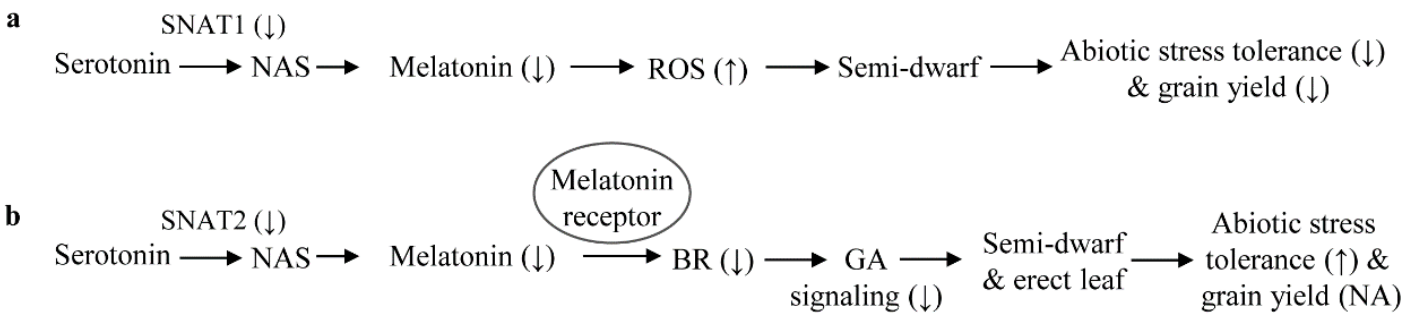

Figure 10. A proposed mechanism for melatonin-mediated abiotic stress tolerance. Two different mechanisms underlie melatonin-mediated plant responses. One mechanism is a BR-independent pathway (a). This pathway is associated directly with the antioxidant activity of melatonin. Melatonin-deficient rice plants, such as snat1, produce increased levels of reactive oxygen species (ROS), which in turn inhibit plant growth and dampen abiotic stress tolerance. The other mechanism is a BR-dependent pathway (b). This pathway involves melatonin as a signaling molecule, possibly via a melatonin receptor [67]. Melatonin-deficient rice plants, such as snat2, exhibit decreased BR levels in conjunction with increased GA insensitivity, leading to enhanced abiotic stress tolerance. The basis of differential receptor recognition of melatonin deficiency caused by either SNAT1 or SNAT2 remains unclear. NAS, $\mathrm{N}$-acetylserotonin; NA, not altered.

\section{Materials and Methods}

\subsection{Plant Materials}

Transgenic rice plants in which expression of the rice SNAT2 gene was downregulated by RNA interference (RNAi) or overexpressed were generated in a previous study [21]. TDC RNAi, T5H knockout mutant, and COMT RNAi rice plants were described previously [23]. TDC RNAi and COMT RNAi rice plants were generated by Agrobacterium-mediated transformation using the same pTCK303 binary vector described previously $[23,69]$. T5H mutant rice plants lacking a functional $T 5 H$ gene were screened from ${ }^{137}$ Cs-irradiated Ashahi seeds and obtained from the National Institute of Agrobiological Sciences (NIAS) GeneBank (http://www.gene.affrc.go.jp/plant/).

\subsection{Plant Growth Conditions}

Wild-type and transgenic rice (Oryza sativa) seeds were soaked in distilled water (DW), and the germinated seeds were transferred onto soil. Plants were grown in a culture room at $28{ }^{\circ} \mathrm{C} / 24{ }^{\circ} \mathrm{C}$ (day/night) with a 14-h light/10-h dark cycle, or in a paddy field at the Chonnam National University (53 $\mathrm{m}$ a.s.l.; $35^{\circ} 09^{\prime} \mathrm{N}$ and $126^{\circ} 54^{\prime} \mathrm{W}$ ), Gwangju, Korea. The angles of the lamina joint of the second leaf were measured in 12-day-old rice seedlings.

\subsection{Semi-Quantitative Reverse Transcription-Polymerase Chain Reaction (RT-PCR) Analysis}

The NucleoSpin RNA Plant Kit (Macherey-Nagel, Düren, Germany) was used to extract total RNA. First-strand cDNA was synthesized from $2 \mu \mathrm{g}$ of total RNA using MG MMLV Reverse Transcriptase (MGmed, Inc., Seoul, Korea) and an oligo dT18 primer at $42^{\circ} \mathrm{C}$ for $1 \mathrm{~h}$. The rice ubiquitin-5 (UBQ5) gene was used as a loading control. PCR was carried out as described previously [19]. The primers used for the various genes were as follows: GA3ox2 (forward 5'-TCCTCCTTCTTCTCCAAGCTCAT-3'; reverse 5'-GAAACTCCTCCATCACGTCACA-3'), GA2ox3 (forward 5'-TGGTGGCCAACAGCCTAAAG-3'; reverse $5^{\prime}$-TGGTGCAATCCTCTGTGCTAAC-3'), DWARF4 (forward 5'-GTGCTGCCATTCTCG GAGTAATAG-3'; reverse 5'-CTCAGCAAGAGGTCCAGGATTTGC-3'), IAA6 (forward 5'-CACC ATGGAAGAAGGGTCCAACAAAA- ${ }^{\prime}$; reverse $5^{\prime}$-TTAGACCCTAGCAGTAGCTCCA-3'), and UBQ5 (forward 5'-CCGACTACAACATCCAGAAGGAG-3'; reverse 5' -AACAGGAGCCTACGCCTAAGC-3'). 
GenBank accession numbers are AB056519 (GA3ox2), AK101713 (GA2ox3), Os03g12660 (DWARF4), Os01g0741900 (IAA6), and AK061988 (UBQ5).

\subsection{Hormone Treatment}

Gibberellic acid $\left(\mathrm{GA}_{3}\right)$ and paclobutrazol (PAC) (Sigma-Aldrich, St. Louis, MO, USA) were dissolved in ethanol. An identical volume of the blank solvent (ethanol) was used as a mock treatment. To detect GA sensitivity, sterilized seeds were first soaked in $150 \mu \mathrm{M}$ PAC for 2 days to inhibit endogenous GA biosynthesis, and then germinated seeds were grown in DW with various concentrations of GA3. Seedling lengths were measured after 7 days of growth.

\subsection{Melatonin Quantification}

Rice samples $(100 \mathrm{mg})$ were frozen in liquid nitrogen and pulverized to a powder using TissueLyser II (Qiagen, Tokyo, Japan), and extracted with $1 \mathrm{~mL}$ of chloroform at room temperature as described previously [70]. In brief, the chloroform extracts $(200 \mu \mathrm{L})$ were completely evaporated and dissolved in $0.1 \mathrm{~mL}$ of $40 \%$ methanol, and $10-\mu \mathrm{L}$ aliquots were subjected to high performance liquid chromatography coupled with a fluorescence detector system (Waters, Milford, MA, USA). Melatonin was detected at $280 \mathrm{~nm}$ (excitation) and $348 \mathrm{~nm}$ (emission). The detection limit and recovery rate of melatonin were approximately $0.25 \mathrm{ng} / \mathrm{g} \mathrm{FW}$ and $90 \%$, respectively, using this analytical method. All measurements were made in triplicate.

\subsection{Germination Assay}

Wild-type and transgenic rice seeds were sterilized with 100\% ethanol for $1 \mathrm{~min}$ followed by $2 \%$ sodium hypochlorite for $5 \mathrm{~min}$. The seeds were then rinsed three times in DW for $30 \mathrm{~min}$. Thirty-five seeds were placed in $3 \mathrm{~mL}$ of DW in six-well plates. Germination tests were carried out in a culture room at $28{ }^{\circ} \mathrm{C} / 24{ }^{\circ} \mathrm{C}$ (day/night) with a 14 -h light/10-h dark cycle. A seed was considered to be germinated when the seed coat ruptured and the radicle was emerged and $>1 \mathrm{~mm}$ in length. Each treatment was repeated three times.

\subsection{Salt, Cold, Heat, and Cadmium Stress Tolerance Assays}

Wild-type and transgenic plants were grown in a culture room with $30 \mu \mathrm{mol}$ photons $\cdot \mathrm{m}^{-2} \cdot \mathrm{s}^{-1}$ at $26^{\circ} \mathrm{C} / 24^{\circ} \mathrm{C}$ (day/night) under a 14-h light/10-h dark photoperiod. For salt stress assays, 10-day-old seedlings grown in pots were irrigated with $200 \mathrm{mM} \mathrm{NaCl}$ for 6 days and then allowed to recover for another 5 days. For cold stress assays, 10-day-old seedlings grown in pots were exposed to $6-8{ }^{\circ} \mathrm{C}$ for 6 days and then allowed to recover for another 14 days at $25-28^{\circ} \mathrm{C}$. For heat stress assays, 10 -day-old seedlings grown in pots were exposed to $42{ }^{\circ} \mathrm{C}$ for 2 days and then allowed to recover for 1 day at $25-28^{\circ} \mathrm{C}$. For cadmium stress assays, 7 -day-old seedlings were placed in $50-\mathrm{mL}$ polypropylene conical tubes containing $30 \mathrm{~mL}$ of $0.5 \mathrm{mM} \mathrm{CdCl}_{2}$ and incubated for 3 days under long day (LD) conditions (14-h light/10-h-dark photoperiod with $60 \mu \mathrm{mol}$ photons $\cdot \mathrm{m}^{-2} \cdot \mathrm{s}^{-1}$ ).

\subsection{Determination of Chlorophyll and Malondialdehyde (MDA) Contents}

Rice samples were frozen in liquid nitrogen and ground to a powder using TissueLyser II (Qiagen). Chlorophyll was extracted from the powder $\left(100 \mathrm{mg}\right.$ ) in $1 \mathrm{~mL}$ of $0.1 \mathrm{M} \mathrm{NH}_{4} \mathrm{OH}$ (containing $80 \%$ acetone). Chlorophyll concentrations were determined at wavelengths of 647, 644, and $750 \mathrm{~nm}$ using a spectrophotometer (Optizen Pop-Bio; Mecasys, Daejeon, Korea). For MDA quantification, the powder (50 mg) was extracted with $1.5 \mathrm{~mL}$ of reaction buffer containing $0.5 \%$ thiobarbituric acid (TBA) and $20 \%$ trichloroacetic acid (TCA). The samples were centrifuged for $15 \mathrm{~min}$ at $12,000 \times g$, and the resulting supernatants were collected for measurement. The supernatant was boiled at $95^{\circ} \mathrm{C}$ for $25 \mathrm{~min}$ and placed in ice for $5 \mathrm{~min}$. MDA content was determined at 440,532, and $600 \mathrm{~nm}$ using a spectrophotometer (Optizen Pop-Bio) and a molar extinction coefficient of $156 \mathrm{nM} \cdot \mathrm{cm}^{-1}$. 


\subsection{Quantification of Bioactive BRs and GA}

Levels of bioactive BRs and GA were quantified with a quantitative sandwich enzyme-linked immunosorbent assay (ELISA) kit (MyBioSource, San Diego, CA, USA). Briefly, 10-day-old rice seedlings $(100 \mathrm{mg})$ were pulverized in liquid nitrogen and homogenized in $1 \mathrm{~mL}$ of phosphate-buffered saline (PBS) ( $\mathrm{pH} 7.5$; Sigma-Aldrich). The resulting samples were centrifuged for $20 \mathrm{~min}$ at $5000 \times g$, and the supernatants were collected for measurement. The supernatants $(100 \mu \mathrm{L})$ were subjected to ELISA according to the manufacturer's instructions (MyBioSource). Optical density was measured at $450 \mathrm{~nm}$ using a microplate reader (Molecular Devices, Sunnyvale, CA, USA), as described previously [71].

\subsection{Statistical Analysis}

Data were analyzed by analysis of variance using IBM SPSS Statistics software (ver. 23.0; IBM Corp., Armonk, NY, USA). Means with different letters or asterisks indicate significantly different values at $p$ $<0.05$ according to a post-hoc Tukey's honestly significant difference (HSD) test or least significance difference (LSD) test. All data are presented as means \pm standard deviation.

Author Contributions: O.J.H. carried out the experiments. K.B. designed, advised and wrote the article.

Funding: This research was supported by grants from the Next-Generation BioGreen 21 Program (SSAC Project No. PJ01325501) via the Rural Development Administration, as well as the Basic Science Research Program of the National Research Foundation of Korea, funded by the Ministry of Education, Republic of Korea (2017R1A2A2A05069253).

Conflicts of Interest: The authors declare that there are no conflicts of interest.

\section{References}

1. Dubbels, R.; Reiter, R.J.; Klenke, E.; Goebel, A.; Schnakenberg, E.; Ehlers, C.; Schiwara, H.W.; Schloot, W. Melatonin in edible plants identified by radioimmunoassay and by high performance liquid chromatography-mass spectrometry. J. Pineal Res. 1995, 18, 28-31. [CrossRef] [PubMed]

2. Hattori, A.; Migitaka, H.; Iigo, M.; Itoh, M.; Yamamoto, K.; Ohtani-Kaneko, R.; Hara, M.; Suzuki, T.; Reiter, R.J. Identification of melatonin in plants and its effects on plasma melatonin levels and binding to melatonin receptors in vertebrates. Biochem. Mol. Biol. Int. 1995, 35, 627-634. [PubMed]

3. Debnath, B.; Islam, W.; Li, M.; Sun, Y.; Lu, X.; Mitra, S.; Hussain, M.; Liu, S.; Qiu, D. Melatonin mediates enhancement of stress tolerance in plants. Int. J Mol. Sci. 2019, 20, 1040. [CrossRef] [PubMed]

4. Wang, Y.; Reiter, R.J.; Chan, Z. Phytomelatonin: A universal abiotic stress regulator. J. Exp. Bot. 2018, 69, 963-974. [CrossRef] [PubMed]

5. Reiter, R.J.; Tan, D.X.; Sharma, R. Historical perspective and evaluation of the mechanisms by which melatonin mediates seasonal reproduction in mammals. Melatonin Res. 2018, 1, 59-77. [CrossRef]

6. Tan, D.X.; Reiter, R.J. Mitochondria: The birth place, battle ground and the site of melatonin metabolism in cells. Melatonin Res. 2019, 2, 44-66. [CrossRef]

7. Manchester, L.C.; Tan, D.X.; Reiter, R.J.; Park, W.; Monis, K.; Qi, W. High levels of melatonin in the seeds of edible plants: Possible function in germ cell protection. Life Sci. 2000, 67, 3023-3029. [CrossRef]

8. Kolář, J.; Johnson, C.H.; Macháčková, I. Exogenously applied melatonin (N-acetyl-5-methoxytryptamine) affects flowering of the short-day plant Chenopodium rubrum. Physiol. Plant. 2003, 118, 605-612. [CrossRef]

9. Lei, X.Y.; Zhu, R.Y.; Zhang, G.Y.; Dai, Y.R. Attenuation of cold-induced apoptosis by exogenous melatonin in carrot suspension cells: The possible involvement of polyamines. J. Pineal Res. 2004, 36, 126-131. [CrossRef]

10. Posmyk, M.M.; Balabusta, M.; Wieczorek, M.; Sliwinska, E.; Janas, K.M. Melatonin applied to cucumber (Cucumis sativus L.) seeds improves germination during chilling stress. J. Pineal Res. 2009, 46, $214-223$. [CrossRef]

11. Hernández-Ruiz, J.; Cano, A.; Arnao, M.B. Melatonin: A growth-stimulating compound present in lupin tissues. Planta 2004, 220, 140-144. [CrossRef]

12. Hernández-Ruiz, J.; Cano, A.; Arnao, M.B. Melatonin acts as a growth-stimulating compound in some monocot species. J. Pineal Res. 2005, 39, 137-142. [CrossRef] [PubMed] 
13. Li, J.; Liu, J.; Zhu, T.; Zhao, C.; Li, L.; Chen, M. The role of melatonin in salt stress responses. Int. J. Mol. Sci. 2019, 20, 1735. [CrossRef] [PubMed]

14. Okazaki, M.; Higuchi, K.; Hahawa, Y.; Shiraiwa, Y.; Ezura, H. Cloning and characterization of a Chlamydomonas reinhardtii cDNA arylalkylamine $N$-acetyltransferase and its use in the genetic engineering of melatonin content in the Micro-Tom tomato. J. Pineal Res. 2009, 46, 373-382. [CrossRef] [PubMed]

15. Wang, Y.; Ji, J.; Bu, H.; Zhao, Y.; Xu, Y.; Johnson, C.H.; Kolár, J. Genetic transformation of Nicotiana tabacum L. by Agrobacterium tumefaciens carrying genes in the melatonin biosynthesis pathway and the enhancement of antioxidative capability in transgenic plants. Chin. J. Biotechnol. 2009, 25, 1014-1021.

16. Back, K.; Tan, D.X.; Reiter, R.J. Melatonin biosynthesis in plants: Multiple pathways catalyze tryptophan to melatonin in the cytoplasm or chloroplasts. J. Pineal Res. 2016, 61, 426-437. [CrossRef] [PubMed]

17. Kang, K.; Kong, K.; Park, S.; Natsagdorj, U.; Kim, Y.S.; Back, K. Molecular cloning of a plant N-acetylserotonin methyltransferase and its expression characteristics in rice. J. Pineal Res. 2011, 50, 304-309. [CrossRef]

18. Kang, K.; Lee, K.; Park, S.; Byeon, Y.; Back, K. Molecular cloning of rice serotonin $N$-acetyltransferase, the penultimate gene in plant melatonin biosynthesis. J. Pineal Res. 2013, 55, 7-13. [CrossRef]

19. Byeon, Y.; Lee, H.Y.; Back, K. Cloning and characterization of the serotonin N-acetyltransferase-2 gene (SNAT2) in rice (Oryza sativa). J. Pineal Res. 2016, 61, 198-207. [CrossRef]

20. Byeon, Y.; Lee, K.; Park, Y.I.; Park, S.; Back, K. Molecular cloning and functional analysis of serotonin $N$-acetyltransferase from the cyanobacterium Synechocystis sp. PCC 6803. J. Pineal Res. 2013, 55, 371-376.

21. Hwang, O.J.; Back, K. Melatonin is involved in skotomorphogenesis by regulating brassinosteroid biosynthesis in plants. J. Pineal Res. 2018, 65, e12495. [CrossRef] [PubMed]

22. Byeon, Y.; Back, K. Low melatonin production by suppression of either serotonin $N$-acetyltransferase or $\mathrm{N}$-acetylserotonin methyltransferase in rice causes seedling growth retardation with yield penalty, abiotic stress susceptibility, and enhanced coleoptile growth under anoxic conditions. J. Pineal Res. 2016, 60, 348-359. [PubMed]

23. Lee, K.; Back, K. Melatonin-deficient rice plants show a common semidwarf phenotype either dependent or independent of brassinosteroid biosynthesis. J. Pineal Res. 2019, 66, e12537. [CrossRef] [PubMed]

24. Zhao, D.; Yu, Y.; Shen, Y.; Liu, Q.; Zhao, Z.; Sharma, R.; Reiter, R.J. Melatonin synthesis and function: Evolutionary history in animals and plants. Front. Endocrinol. 2019, 10, 249. [CrossRef] [PubMed]

25. Sharif, R.; Xie, C.; Zhang, H.; Arnao, M.B.; Ali, M.; Ali, Q.; Muhammad, I.; Shalmani, A.; Nawaz, M.A.; Chen, P.; et al. Melatonin and its effects on plant systems. Molecules 2018, 23, 2352. [CrossRef]

26. Jaillais, Y.; Vert, G. Brassinosteroids, gibberellins and light-mediated signaling are the three-way controls of plant sprouting. Nat. Cell Biol. 2012, 14, 788-790. [CrossRef]

27. Saini, S.; Sharma, I.; Pati, P.K. Versatile roles of brassinosteroid in plants in the context of its homoeostasis, signaling and crosstalks. Front. Plant Sci. 2015, 6, 950. [CrossRef]

28. Vardhini, B.V.; Anuradha, S.; Sujatha, E.; Rao, S.S.R. Role of brassinosteroids in alleviating various abiotic and biotic stresses-a review. Plant Stress 2010, 4, 55-61.

29. Kim, S.Y.; Kim, B.H.; Lim, C.J.; Lim, C.O.; Nam, K.H. Constitutive activation of stress-inducible genes in a brassinosteroid-insensitive 1 (bri1) mutant results in higher tolerance to cold. Physiol. Plant. 2010, 138, 191-204. [CrossRef]

30. Chung, Y.; Kwon, S.I.; Choe, S. Antagonistic regulation of Arabidopsis growth by brassinosteroids and abiotic stresses. Mol. Cells 2014, 37, 795-803. [CrossRef]

31. Northey, J.G.B.; Liang, S.; Jamshed, M.; Deb, S.; Foo, E.; Reid, J.B.; McCourt, P.; Samuel, M.A. Farnesylation mediates brassinosteroid biosynthesis to regulate abscisic acid responses. Nat. Plants 2016, 2, 16114. [CrossRef] [PubMed]

32. Lee, K.; Back, K. Overexpression of rice serotonin $N$-acetyltransferase 1 in transgenic rice plants confers resistance to cadmium and senescence and increases grain yield. J. Pineal Res. 2017, 62, e12392. [CrossRef] [PubMed]

33. Je, B.I.; Piao, H.L.; Park, S.J.; Park, S.H.; Kim, C.M.; Xuan, Y.H.; Park, S.H.; Huang, J.; Choi, Y.D.; An, G.; et al. RAV-like1 maintains brassinosteroid homeostasis via the coordinated activation of BRI1 and biosynthetic genes in rice. Plant Cell 2010, 22, 1777-1791. [CrossRef] [PubMed] 
34. Hong, Z.; Ueguchi-Tanaka, M.; Umemura, K.; Uozu, S.; Fujioka, S.; Takatsuto, S.; Yoshida, S.; Ashikari, M.; Kitano, H.; Matsuoka, M. A rice brassinosteroid-deficient mutant, ebisu dwarf (d2), is caused by a loss of function of a new member of cytochrome P450. Plant Cell 2003, 15, 2900-2910. [CrossRef] [PubMed]

35. Tanabe, S.; Ashikari, M.; Fujioka, S.; Takatsuto, S.; Yoshida, S.; Yano, M.; Yoshimura, A.; Kitano, H.; Matsuoka, M.; Fujisawa, Y.; et al. A novel cytochrome P450 is implicated in brassinosteroid biosynthesis via the characterization of a rice dwarf mutant, dwarf11, with reduced seed length. Plant Cell 2005, 17, 776-790. [CrossRef]

36. Morinaka, Y.; Sakamoto, T.; Inukai, Y.; Agetsuma, M.; Kitano, H.; Ashikari, M.; Matsuoka, M. Morphological alteration caused by brassinosteroid insensitivity increases the biomass and grain production in rice. Plant Physiol. 2006, 141, 924-931. [CrossRef]

37. Sakamoto, T.; Morinaka, Y.; Ohnishi, T.; Sunohara, H.; Fujioka, S.; Ueguchi-Tanaka, M.; Mizutani, M.; Sakata, K.; Takatsuto, S.; Yoshida, S.; et al. Erect leaves caused by brassinosteroid deficiency increase biomass production and grain yield in rice. Nat. Biotechnol. 2005, 24, 105-109. [CrossRef]

38. Tong, H.; Xiao, Y.; Liu, D.; Gao, S.; Liu, L.; Yin, Y.; Jin, Y.; Qian, Q.; Chu, C. Brassinosteroid regulates cell elongation by modulating gibberellin metabolism in rice. Plant Cell 2014, 26, 4376-4393. [CrossRef]

39. Hirano, K.; Yoshida, H.; Aya, K.; Kawamura, M.; Hayashi, M.; Hobo, T.; Sato-Izawa, K.; Kitano, H.; Ueguchi-Tanaka, M.; Matsuoka, M. SMALL ORGAN SIZE 1 and SMALL ORGAN SIZE 2/DWARF and LOW-TILLERING Form a complex to integrate auxin and brassinosteroid signaling in rice. Mol. Plant 2017, 10, 590-604. [CrossRef]

40. Jung, H.; Lee, D.-K.; Choi, Y.D.; Kim, J.-K. OsIAA6, a member of the rice Aux/IAA gene family, is involved in drought tolerance and tiller outgrowth. Plant Sci. 2015, 236, 304-312.

41. Gruszka, D.; Janeczko, A.; Dziurka, M.; Pociecha, E.; Okestkova, J.; Szarejko, I. Barley brassinosteroid mutants provide an insight into phytohormonal homeostasis in plant reaction to drought stress. Front. Plant Sci. 2016, 7, 1824. [CrossRef] [PubMed]

42. Colebrook, E.H.; Thomas, S.G.; Phillips, A.L.; Hedden, P. The role of gibberellin signaling in plant responds to abiotic stress. J. Exp. Biol. 2014, 217, 67-75. [CrossRef] [PubMed]

43. Reina, M.; Castañeda-Arriaga, R.; Perez-Gonzalez, A.; Guzman-Lopez, E.G.; Tan, D.X.; Reiter, R.J.; Galano, A. A computer-assisted systematic search for melatonin derivatives with high potential as antioxidants. Melatonin Res. 2018, 1, 27-58. [CrossRef]

44. Li, C.; Wang, P.; Wei, Z.; Liang, D.; Liu, C.; Yin, L.; Jia, D.; Fu, M.; Ma, F. The mitigation effects of exogenous melatonin on salinity-induced stress in Malus hupehensis. J. Pineal Res. 2012, 53, 298-306. [CrossRef] [PubMed]

45. Turk, H.; Erdal, S.; Genisel, M.; Atici, O.; Demir, Y.; Yanmis, D. The regulatory effect of melatonin on physiological, biochemical and molecular parameters in cold-stressed wheat seedlings. Plant Growth Regul. 2014, 74, 139-152. [CrossRef]

46. Ullah, M.A.; Tungmunnithum, D.; Garros, L.; Drouet, S.; Hano, C.; Abbasi, B.H. Effect of ultraviolet-C radiation and melatonin stress on biosynthesis of antioxidant and antidiabetic metabolites produced in in vitro callus cultures of Lepidium sativum L. Int. J. Mol. Sci. 2019, 20, 1787. [CrossRef]

47. Wang, P.; Sun, X.; Wang, N.; Tan, D.X.; Ma, F. Melatonin enhances the occurrence of autophagy induced by oxidative stress in Arabidopsis seedlings. J. Pineal Res. 2015, 58, 479-489. [CrossRef]

48. Qi, Z.Y.; Wang, K.X.; Yan, M.Y.; Kanwar, M.K.; Li, D.Y.; Wijaya, L.; Alyemeni, M.N.; Ahmad, P.; Zhou, J. Melatonin alleviates high temperature-induced pollen abortion in Solanum lycopersicum. Molecules 2018, 23, 386. [CrossRef]

49. Lee, H.Y.; Back, K. Melatonin plays a pivotal role in conferring tolerance against endoplasmic reticulum stress via mitogen-activated protein kinases and bZIP60 in Arabidopsis thaliana. Melatonin Res. 2018, 1, 93-107. [CrossRef]

50. Kang, K.; Lee, K.; Park, S.; Kim, Y.S.; Back, K. Enhanced production of melatonin by ectopic overexpression of human serotonin $\mathrm{N}$-acetyltransferase plays a role in cold resistance in transgenic rice seedlings. J. Pineal Res. 2010, 49, 176-182. [CrossRef]

51. Zhang, L.J.; Jia, J.F.; Xu, Y.; Wang, Y.; Hao, J.G.; Li, T.K. Production of transgenic Nicotiana sylvestris plants expressing melatonin synthetase genes and their effect on UV-induced DNA damage. In Vitro Cell Dev. Biol. Plant 2012, 48, 275-283. [CrossRef] 
52. Park, S.; Lee, D.E.; Jang, H.; Byeon, Y.; Kim, Y.S.; Back, K. Melatonin-rich transgenic rice plants exhibit resistance to herbicide-induced oxidative stress. J. Pineal Res. 2013, 54, 258-263. [CrossRef] [PubMed]

53. Wang, L.; Zhao, Y.; Reiter, R.J.; He, C.; Liu, G.; Lei, Q.; Zuo, B.; Zheng, X.D.; Li, Q.; Kong, J. Change in melatonin levels in transgenic 'Micro-Tom' tomato over-expressing ovine AANAT and ovine HIOMT genes. J. Pineal Res. 2014, 56, 134-142. [CrossRef] [PubMed]

54. Zuo, B.; Zheng, X.; He, P.; Wang, L.; Lei, Q.; Feng, C.; Zhou, J.; Li, Q.; Han, Z.; Kong, J. Overexpression of MzASMT improves melatonin production and enhances drought tolerance in transgenic Arabidopsis thaliana plants. J. Pineal Res. 2014, 57, 408-417. [CrossRef] [PubMed]

55. Yang, W.-J.; Du, Y.-T.; Zhou, Y.-B.; Chen, J.; Xu, Z.-S.; Ma, Y.-Z.; Chen, M.; Min, D.-H. Overexpression of TaCOMT improves melatonin production and enhances drought tolerance in transgenic Arabidopsis. Int. J. Mol. Sci. 2019, 20, 652. [CrossRef] [PubMed]

56. Xu, W.; Cai, S.Y.; Zhang, Y.; Wang, Y.; Ahammed, G.J.; Xia, X.J.; Shi, K.; Zhou, Y.H.; Yu, J.Q.; Reiter, R.J.; et al. Melatonin enhances thermotolerance by promoting cellular protein protection in tomato plants. J. Pineal Res. 2016, 61, 457-469. [CrossRef]

57. Zheng, X.; Tan, D.X.; Allan, A.C.; Zuo, B.; Zhao, Y.; Reiter, R.J.; Wang, L.; Wang, Z.; Guo, Y.; Zhou, J.; et al. Chloroplastic biosynthesis of melatonin and its involvement in protection of plants from salt stress. Sci. Rep. 2017, 7, 41236. [CrossRef]

58. Li, M.Q.; Hasan, M.K.; Li, C.X.; Ahammed, G.J.; Xia, X.J.; Shi, K.; Zhou, Y.H.; Reiter, R.J.; Yu, J.Q.; Xu, M.X.; et al. Melatonin mediates selenium-induced tolerance to cadmium stress in tomato plants. J. Pineal Res. 2016, 61, 291-302. [CrossRef]

59. Gu, Q.; Chen, Z.; Yu, X.; Cui, W.; Pan, J.; Zhao, G.; Xu, S.; Wang, R.; Shen, W. Melatonin confers plant tolerance against cadmium stress via the decrease of cadmium accumulation and reestablishment of microRNA-mediated redox homeostasis. Plant Sci. 2017, 261, 28-37. [CrossRef]

60. Cai, S.Y.; Zhang, Y.; Xu, Y.P.; Qi, Z.Y.; Li, M.Q.; Ahammed, G.J.; Xia, X.J.; Shi, K.; Zhou, Y.H.; Reiter, R.J.; et al. HsfA1a upregulates melatonin biosynthesis to confer cadmium tolerance in tomato plants. J. Pineal Res. 2017, 62, e12387. [CrossRef]

61. Choi, G.-H.; Lee, H.Y.; Back, K. Chloroplast overexpression of rice caffeic acid O-methyltransferase increase melatonin production in chloroplasts via the 5-methoxytryptamine pathway in transgenic rice plants. J. Pineal Res. 2017, 63, e12412. [CrossRef] [PubMed]

62. Lee, H.Y.; Back, K. Melatonin induction and its role in high light stress tolerance in Arabidopsis thaliana. J. Pineal Res. 2018, 65, e12504. [CrossRef] [PubMed]

63. Chen, Z.; Xie, Y.; Gu, Q.; Zhao, G.; Zhang, Y.; Cui, W.; Xu, S.; Wang, R.; Shen, W. The AtrbohF-dependent regulation of ROS signaling is required for melatonin-induced salinity tolerance in Arabidopsis. Free Radic. Biol. Med. 2017, 108, 465-477. [CrossRef] [PubMed]

64. Lee, H.Y.; Back, K. Melatonin is required for $\mathrm{H}_{2} \mathrm{O}_{2}$ - and NO-mediated defense signaling through MAPKKK3 and OXI1 in Arabidopsis thaliana. J. Pineal Res. 2017, 62, e12379. [CrossRef]

65. Sharma, I.; Kaur, N.; Pati, P.K. Brassinosteroids: A promising option in deciphering remedial strategies for abiotic stress tolerance in rice. Front. Plant Sci. 2017, 8, 2151. [CrossRef]

66. Nakashita, H.; Yasuda, M.; Nitta, T.; Asami, T.; Fujioka, S.; Aria, Y.; Sekimata, K.; Takatsuto, S.; Yamaguchi, I.; Yoshida, S. Brassinosteroid functions in a broad range of disease resistance in tobacco and rice. Plant J. 2003, 33, 887-898. [CrossRef]

67. Tian, H.; Lv, B.; Ding, T.; Bai, M.; Ding, Z. Auxin-BR interaction regulates plant growth and development. Front. Plant Sci. 2018, 8, 2256. [CrossRef]

68. Wei, J.; Li, D.X.; Zhang, J.R.; Shan, C.; Rengel, Z.; Song, Z.B.; Chen, Q. Phytomelatonin receptor PMTR1-mediated signaling regulates stomatal closure in Arabidopsis thaliana. J. Pineal Res. 2018, 65, e12500. [CrossRef]

69. Choi, G.-H.; Back, K. Suppression of melatonin 2-hydroxylase increases melatonin production leading to the enhanced abiotic stress tolerance against cadmium, senescence, salt, and tunicamycin in rice plants. Biomolecules 2019, 9, 589. [CrossRef] 
70. Lee, K.; Choi, G.H.; Back, K. Cadmium-induced melatonin synthesis in rice requires light, hydrogen peroxide, and nitric oxide: Key regulatory roles for tryptophan decarboxylase and caffeic acid $O$-methyltransferase. J. Pineal Res. 2017, 63, e12441. [CrossRef]

71. Wang, S.; Liu, J.; Zhao, T.; Du, C.; Nie, S.; Zhang, Y.; Lv, S.; Huang, S.; Wang, X. Modification of threonine-1050 of SIBRI1 regulates BT signaling and increases fruit yield of tomato. BMC Plant Biol. 2019, 19, 256. [CrossRef] [PubMed]

(C) 2019 by the authors. Licensee MDPI, Basel, Switzerland. This article is an open access article distributed under the terms and conditions of the Creative Commons Attribution (CC BY) license (http://creativecommons.org/licenses/by/4.0/). 